\title{
Technique of Dorsal Transversely Oriented Transposition Flap for Web Reconstruction in Toe Syndactyly Surgery
}

\section{$\operatorname{AUTHOR}(\mathrm{S}):$}

Saito, Susumu; Suzuki, Yoshihisa; Suzuki, Shigehiko

\section{CITATION:}

Saito, Susumu ...[et al]. Technique of Dorsal Transversely Oriented Transposition Flap for Web Reconstruction in Toe Syndactyly Surgery. Journal of Foot and Ankle Surgery 2015, 54(6): 1119-1123

\section{ISSUE DATE:}

2015-11

URL:

http://hdl.handle.net/2433/232632

\section{RIGHT:}

(c) 2015. This manuscript version is made available under the CC-BY-NC-ND 4.0 license

http://creativecommons.org/licenses/by-nc-nd/4.0/; The full-text file will be made open to the public on 01 November 2016 in accordance with publisher's 'Terms and Conditions for Self-Archiving'; この論文は出版社版でありません。引用 の際には出版社版をご確認じ利用ください。; This is not the published version. Please cite only the published version. 
1 Title

2 A Technique of Dorsal Transversely-oriented Transposition Flap for Web which can spare the dorsal interdigital skin maximally to shift the dorsal scars planterly syndactylies, especially in cases of high cosmetic priority.

\section{Keywords}

flap, polysyndactyly, surgery, syndactyly, toe 
1

2

3

4

\section{Introduction}

The aim of syndactyly surgery is to reconstruct not only functionally-independent but also cosmetically-pleasing digits. In syndactyly of the toes, surgeries are occasionally indicated to meet patients' and/or parents of patients' cosmetic requests. As in hand syndactyly, reconstructive procedures using a dorsal, or planter commissural flap, in combination with skin grafts, have been employed; however, unsightly longitudinal scars on the dorsum of the toes sometimes fail to satisfy their expectations (Fig. 1). Also, the symmetrical appearance of the dorsal scars remains a reminder that the toes were artificially separated. In an attempt to address these issues, we developed a novel design technique, using a dorsal transversally-oriented transposition flap for web reconstruction. Our technique is described below.

\section{Surgical Technique}

The technique is employed for web creation in toe syndactyly and polysyndactyly of the toes. Surgeries are performed under general anesthesia and tourniquet control. A transversely-oriented flap is designed dorsally on the base of one of the involved toes

(Fig.1). Its pedicle, measuring approximately $5 \mathrm{~mm}$ in width (the width of the flap can be adjusted according to the size of the toes and skin tension), is placed at the proximal third to quarter interdigital space of the proximal phalanx. Two parallel 
1 incisions, constituting both edges of the flap, are made to run transversely and slightly

2 curve distalward to join at the opposite aspect of the toe (Fig. 2(B), Fig. 3(B)). A dorsal

3 zigzag incision is then made distally to create multiple triangular interdigitating flaps.

4 On the planter side, a small triangular flap is designed at the base and a zigzag

5 incision is extended distally in the same manner as on the dorsal side. With care not

6 to injure the underlying adipose layer, the transversely-oriented flap is raised (Fig.

$7 \quad 2(C)$ ) and redirected 90 degrees to be inset into the commissure (Fig. 2(D), Fig. 3(C)).

8 The $\mathrm{V}$-shaped distal tip is trimmed into a rectangular configuration (Fig. 3(D)). After

9 tight closure of the donor site using absorbable dermal sutures, the lateral aspects of

10 the toes are resurfaced with the interdigitating flaps. If skin defects remain, they are

11 covered with full-thickness skin grafts harvested from the submalleolar region. A bulky

12 dressing is applied and the extremity is held in cast immobilization. Sutures are

removed 3 weeks postoperatively. A sponge-pad (Reston ${ }^{\mathrm{TM}}, 3 \mathrm{M}$ Critical \& Chronic

Care Solutions) compression on the commissure is maintained for 3 to 6 months (Fig.

4).

\section{Discussion}

During a period of 6 years, we operated on 11 webs of 8 patients, 5 boys and 3 girls, 
1 corrections of simple syndactyly of the toes, and 2 of postaxial polysyndactyly of the

2 toes. Except for the case of a girl of the age of 13, all the cases were in the age range of 1 to 2 years when surgery was performed. In most of the syndactyly cases, the total

4 surface areas for skin grafts were less than $1.0 \mathrm{~cm}^{2}$, especially for defects of the most

5 proximal portion of the separated surfaces. In polysyndactyly cases, skin grafts were

6 not needed. Neither flap loss nor delay in wound healing was observed in any one

7 case. All the transverse scars of the donor sites became inconspicuous and

8 physiological configuration of the web was reconstructed (Fig. 5(B), Fig. 6(B)). None

9 of the cases showed a substantial scar contracture or web creep during the mean

10 follow-ups of 26 months (range, 12-45).

11 Most published papers regarding toe syndactyly and polysyndactyly of the toes were originated from East Asian countries ${ }^{1-3,6-9}$. Recently, European surgeons, Marsh and Floyd, reported their surgical experiences of toe syndactyly, and investigated patients' satisfaction $^{4}$. The investigation revealed that the patients' concerns about their conditions were successfully reduced after operation, suggesting that if psychological problems of patients with toe syndactyly were highlighted, surgical indication would increase. Originally, corrections of syndactylous conditions of the toes were performed in the almost same maneuvers as for hand syndactyly, such as a dorsal rectangular flap, or 
1 bi-planer rectangular or triangular flaps for web reconstruction ${ }^{1-5}$, in combination with

2 skin grafts for lateral resurfacings. Since the 1990s, two technical variations with

3 different surgical concepts have been advocated: one is an open technique ${ }^{6,7}$, and

4 the other is a graft-less method ${ }^{8,9}$. In the open technique, the residual skin defects of

5 the lateral aspects of the separated toes are intentionally left open to be secondarily

6 healed. This technique shortens the operation time and eliminates the need for

7 postoperative cares for grafts; however, the risk of web creep can be heightened due

8 to wound constriction. Kawabata et al. documented a series of cases treated with the

9 open technique, where a dorsal rectangular flap was made more proximal than usual

10 to compensate for possible web creep ${ }^{6}$. Hirosaka et al. also reported their

11 experiences with the open technique. They mentioned duration of the lateral

12 epithelization averaged 5 weeks ${ }^{7}$. On the other hand, the graft-less method includes

13 variations of island flap techniques, where the newly-created commissure is

14 reconstructed by island flaps, and the lateral raw aspects of the toes are closed

15 primarily with interdigital skin flaps ${ }^{8,9}$. Ito and Arai described a graft-less technique

16 using a planter pentagonal island flap ${ }^{8}$. This flap technique required wide

17 subcutaneous dissections for distalward mobilization. Their surgical indication was

18 limited to cases which had sufficient interdigital skin to close the lateral aspects

19 directly. Moreover, they suggested that especially in syndactyly cases, removal of 
1 interdigital fat tissue was always necessitated to lessen tension in the closure. Lim et

2 al. used a dorsal pentagonal island flap for commissural reconstruction ${ }^{9}$. Their technique successfully achieved functional web creation; however, dorsal longitudinal scars continuing from the base of the web to the dorsum of the metatarsal had a tendency to develop scar hypertrophy or keloid formation.

Considering these technical issues, we developed a surgical concept, which satisfies the functional and aesthetic aspects as followed: a smooth transition from the dorsum of the foot to the commissure to create a physiological slope of the web, no linear scars on the lateral aspects to avoid web creep, no dorsal longitudinal scars to avoid scar hypertrophy, simple design and easy flap elevation. Since 2008, acknowledging the good healing potential of transverse scars, we switched the axis of the traditional rectangular flap from longitudinal to transverse direction. Lateral resurfacing was performed using both interdigitating flaps and skin grafts. By sparing the dorsal interdigital skin maximally, both the dorsal scars and grafted sites were shifted more planterly to be inconspicuous. Furthermore, the asymmetrical appearance of dorsal scars does not reveal the anomalous condition, thereby protecting patients' privacy.

A technical concern regarding our method is that the tapered shape of the flap might pose the potential risk of distal necrosis. We raised the flap with care to preserve the vascular networks in the subcutaneous layer, and held it in place with a bulky dressing 
1 and cast immobilization as in skin grafting. Additionally, the most distal tip of the flap is

2 always trimmed. These procedures minimized the possibility of flap failures. Our surgical concept does not include graft-less reconstruction. In order to eliminate the possibility of future lateral pain caused by the de-fatting maneuver used in the direct

5 lateral closures, we chose not to utilize both the open and the graft-less method. A

6 minimized surface area of skin graft might contribute to lessen the risk of web creep.

7 The limitation of our study is 2-fold. Firstly, is a lack of experiences of complex, or

8 multiple syndactylies of the toes. Secondly, is a limited term of follow-ups. Further

9 data on variations of conditions with long-term follow-ups will clarify the applicability of

10 the technique.

11 In conclusion, the design of the transversely-oriented dorsal transposition flap is simple and uncomplicated surgically. Using this technique, the dorsal interdigital skin can be spared maximally, and the donor site morbidity is minimal, owing to the good healing potential of transverse scars. This technique could be an alternative in web reconstruction of toe syndactylies, especially in cases of high cosmetic priority.

\section{Acknowledgement/s}

None 
1

2

3

\section{References}

1. Nogami H. Polydactyly and polysyndactyly of the fifth toe. Clin Orthop Relat Res. 204:261-265, 1986.

2. Onishi K, Nakajima T, Yoneda K, Aoki T. Operation for polysyndactyly of the fifth toe using Z-plasty. Br J Plast Surg. 45:554-556, 1992.

3. Hayashi A, Yanai A, Komuro Y, Nishida M. A New Surgical Technique for Polysyndactyly of the Toes without Skin Graft. Plast Reconstr Surg. 114:433-438, 2004.

4. Marsh DJ, Floyd D. Toe syndactyly revisited. J Plast Reconstr Aesthet Surg. 64:535-540, 2011.

5. Park S, Eguchi T, Tokioka K, Minegishi M. Reconstruction of incomplete syndactyly of the toes using both dorsal and plantar flaps. Plast Reconstr Surg. 98:534-537, 1996

6. Kawabata $\mathrm{H} 1$, Ariga K, Shibata T, Matsui Y Open treatment of syndactyly of the foot. Scand J Plast Reconstr Surg Hand Surg. 37:150-154, 2003.

7. Hikosaka M1, Ogata H, Nakajima T, Kobayashi H, Hattori N, Onishi F, Tamada I. Advantages of open treatment for syndactyly of the foot: defining its indications. Scand J Plast Reconstr Surg Hand Surg. 43:148-152, 2009.

8. Itoh $\mathrm{Y}$, Arai $\mathrm{K}$. A new operation for syndactyly and polysyndactyly of the foot 
without skin grafts.Br J Plast Surg. 48:306-311, 1995.

9. Lim YJ, Teoh LC, Lee EH. Reconstruction of syndactyly and polysyndactyly of the toes with a dorsal pentagonal island flap: a technique that allows primary skin closure without the use of skin grafting. J Foot Ankle Surg. 46:86-92, 2007.

\section{Figure Legends}

Fig. 1. Illustrations showing the surgical design of the transversely-oriented dorsal transposition flap. Pairs of dot indicate the dorsal peak of the webs.

Fig. 2. A series of photographs showing the process of web reconstruction by the transversely-oriented transposition flap for toe syndactyly. (A) Dorsal view of 1-year-old boy's incomplete syndactyly of the second web of the left foot. (B) The flap, $5 \mathrm{~mm}$ in width, is designed on the dorsum of the second toe. (C) Flap elevation. (D) The flap is redirected $90^{\circ}$ to be inset into the commissure. The both edges of the donor wound are approximated.

Fig. 3. A series of photographs showing the process of web reconstruction by the transversely-oriented transposition flap for postaxial polysyndactyly of the toes. (A) Dorsal view showing a 1-year-old girl's postaxial polysyndactyly of the right foot. (B) After resection of the fifth toe, the transversely-oriented flap is designed on the dorsum of the fourth toe. (C) The flap is redirected $90^{\circ}$ to be inset into the 
1 commissure. The both edges of the donor wound are approximated. (D) After

2 trimming of the distal end of the flap, the flap is inset into the commissure. Lateral

3 resurfacings of the both toes are completed without skin grafting.

4 Fig.4. Postoperative sponge-pad compression applying onto the newly-created

$5 \quad$ commissure. (A) Toe syndactyly. (B) Polysyndactyly of the lessor toes.

6 Fig. 5. Postoperative photographs of toe syndactyly (the same case in Fig. 2) at

7 follow-up of 12 months. (A) The transverse scar at the donor site on the base of the

8 second toe is significantly inconspicuous. (B) The commissure shows no contracture.

9 Fig. 6. Postoperative photographs of polysyndactyly of the toe (the same case in Fig.

3). (A) The transverse scar at the donor site on the base of the forth toe is significantly 


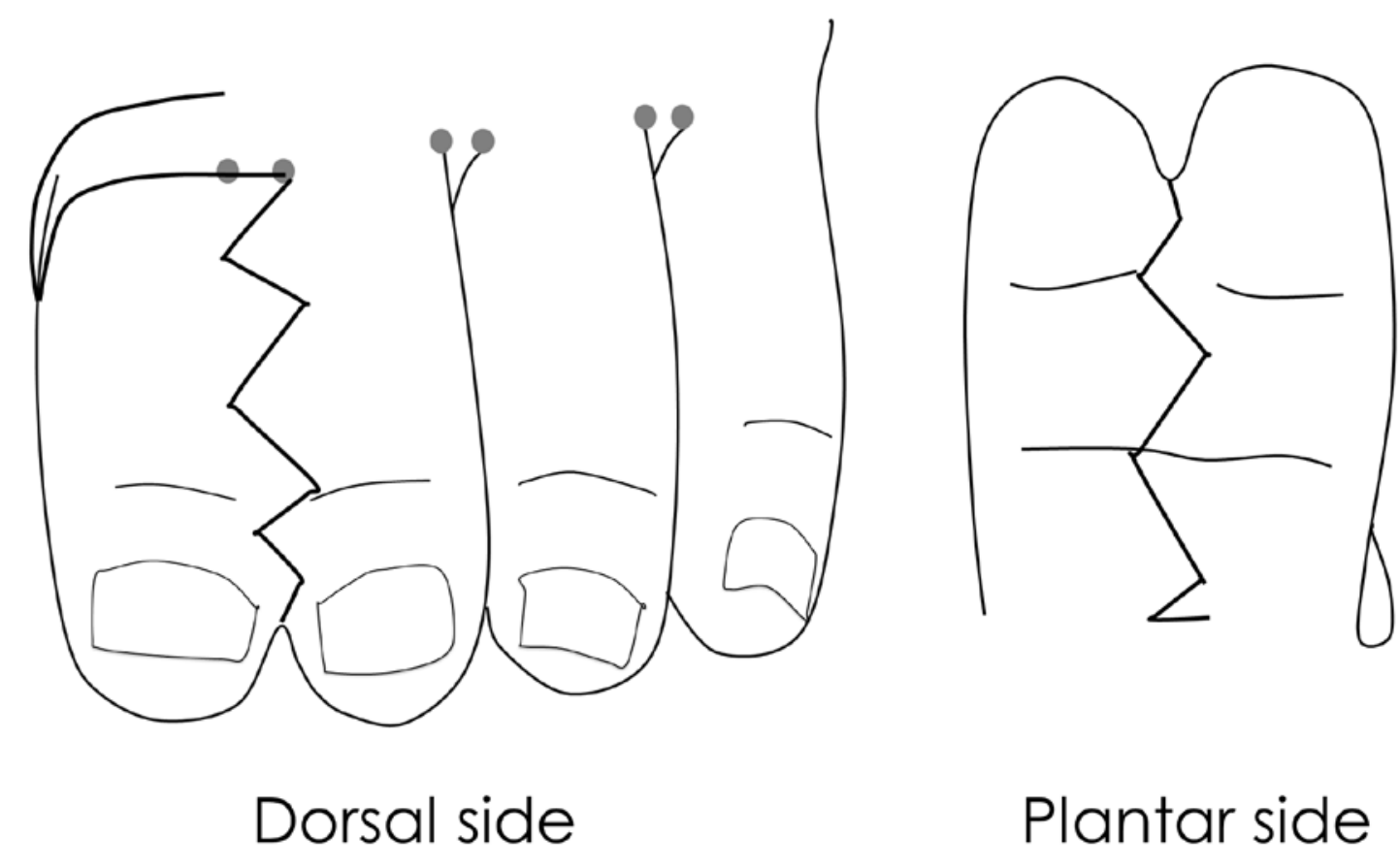

Fig. 1 


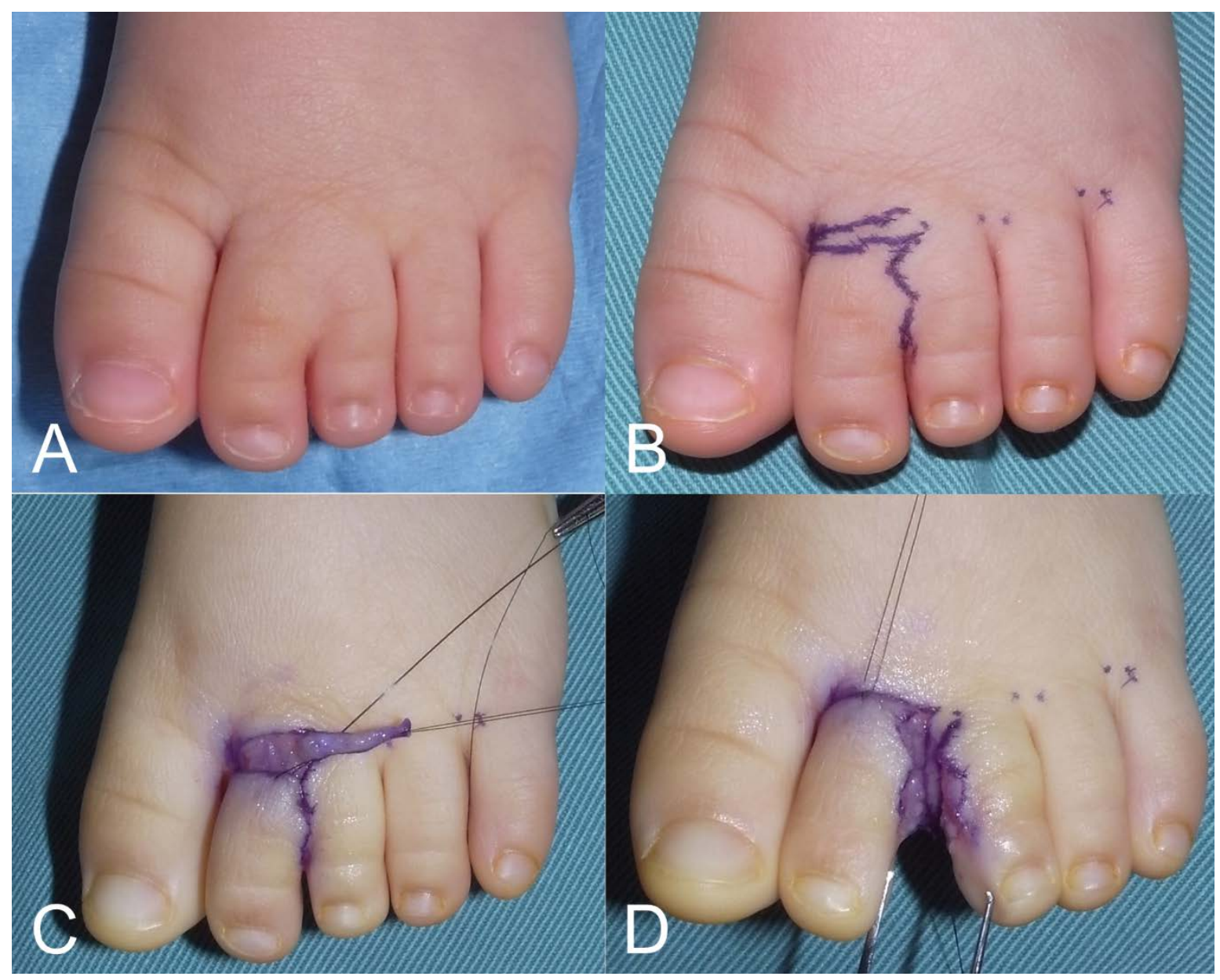

Fig. 2 


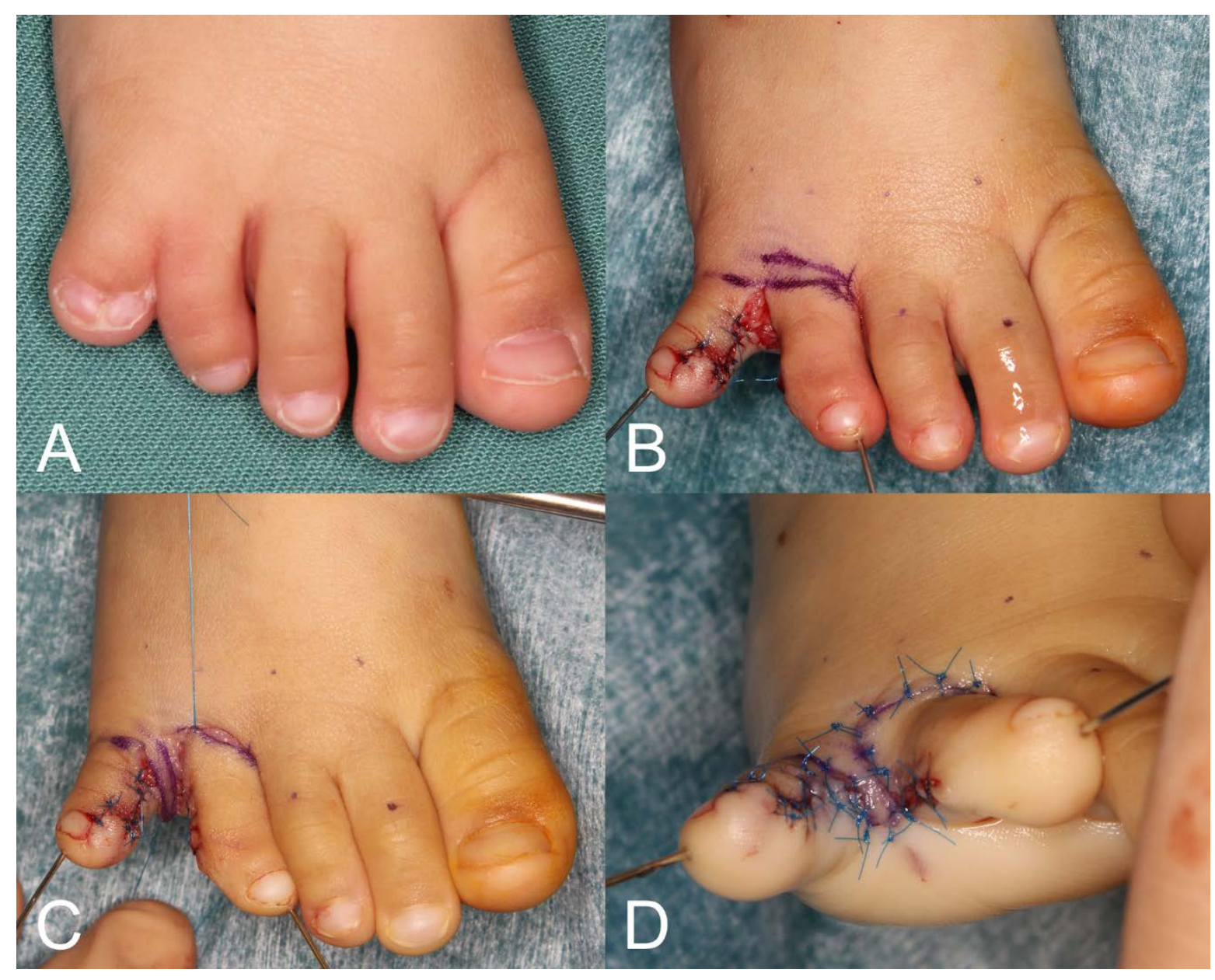

Fig. 3 


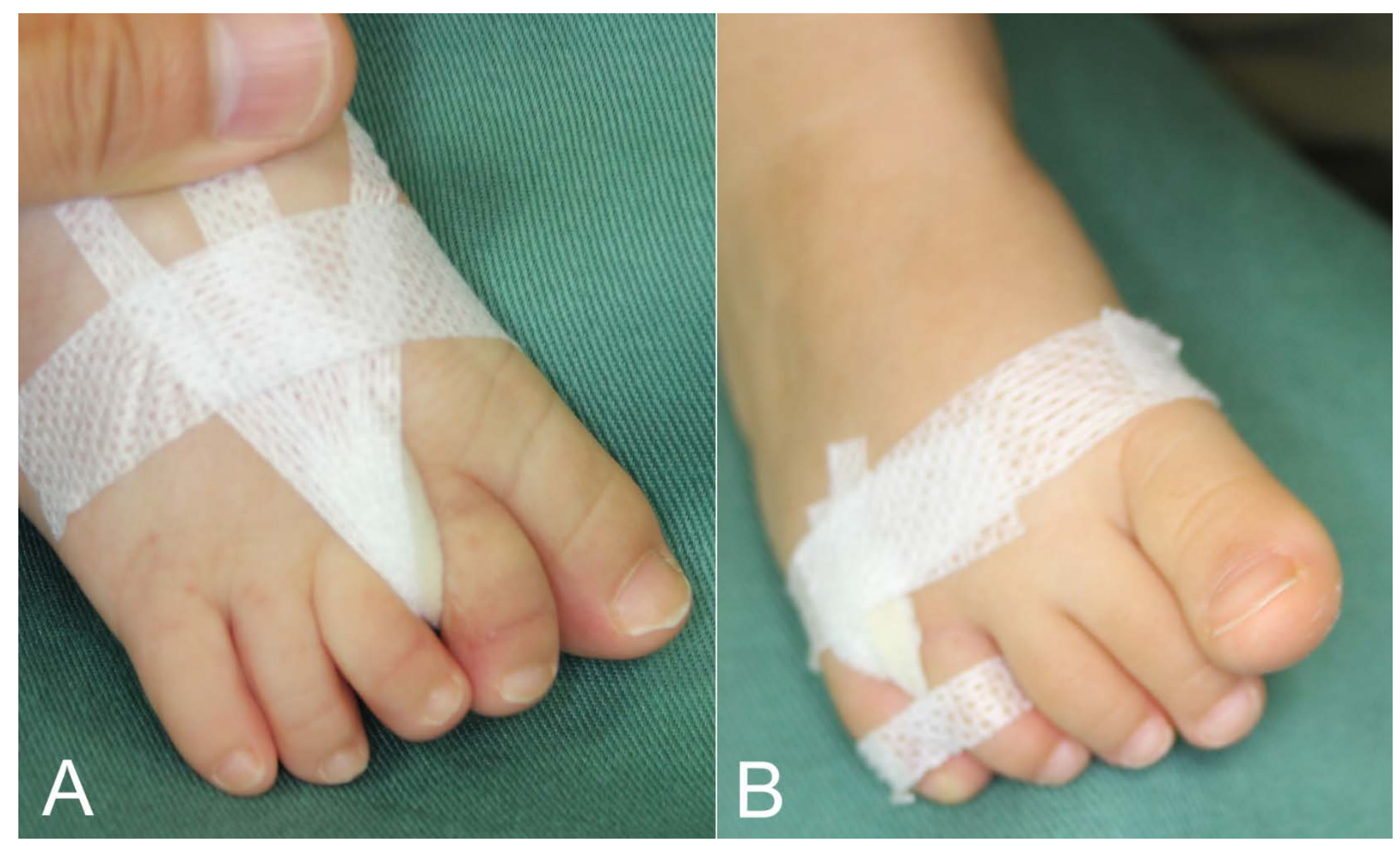

Fig. 4 


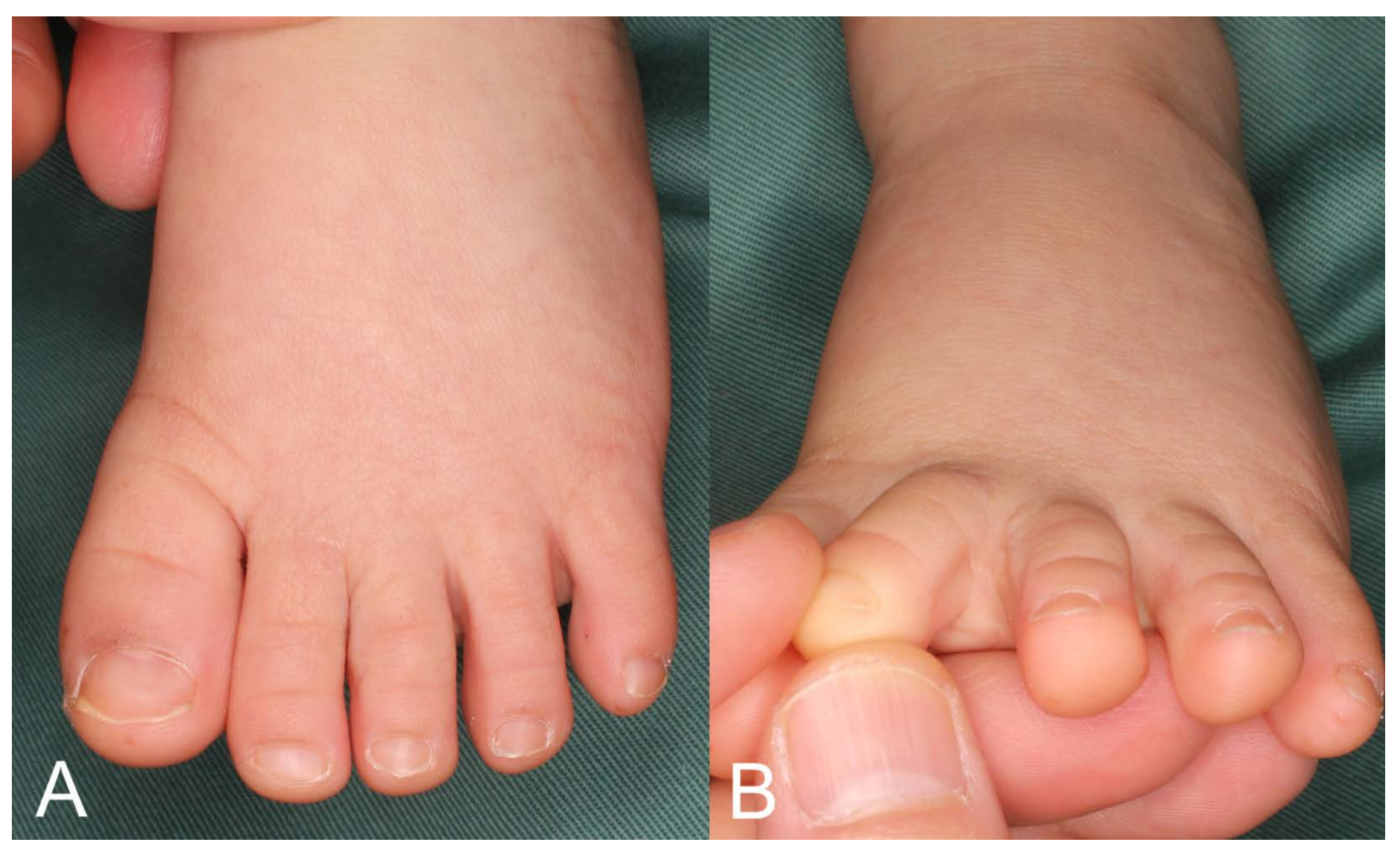

Fig. 5 


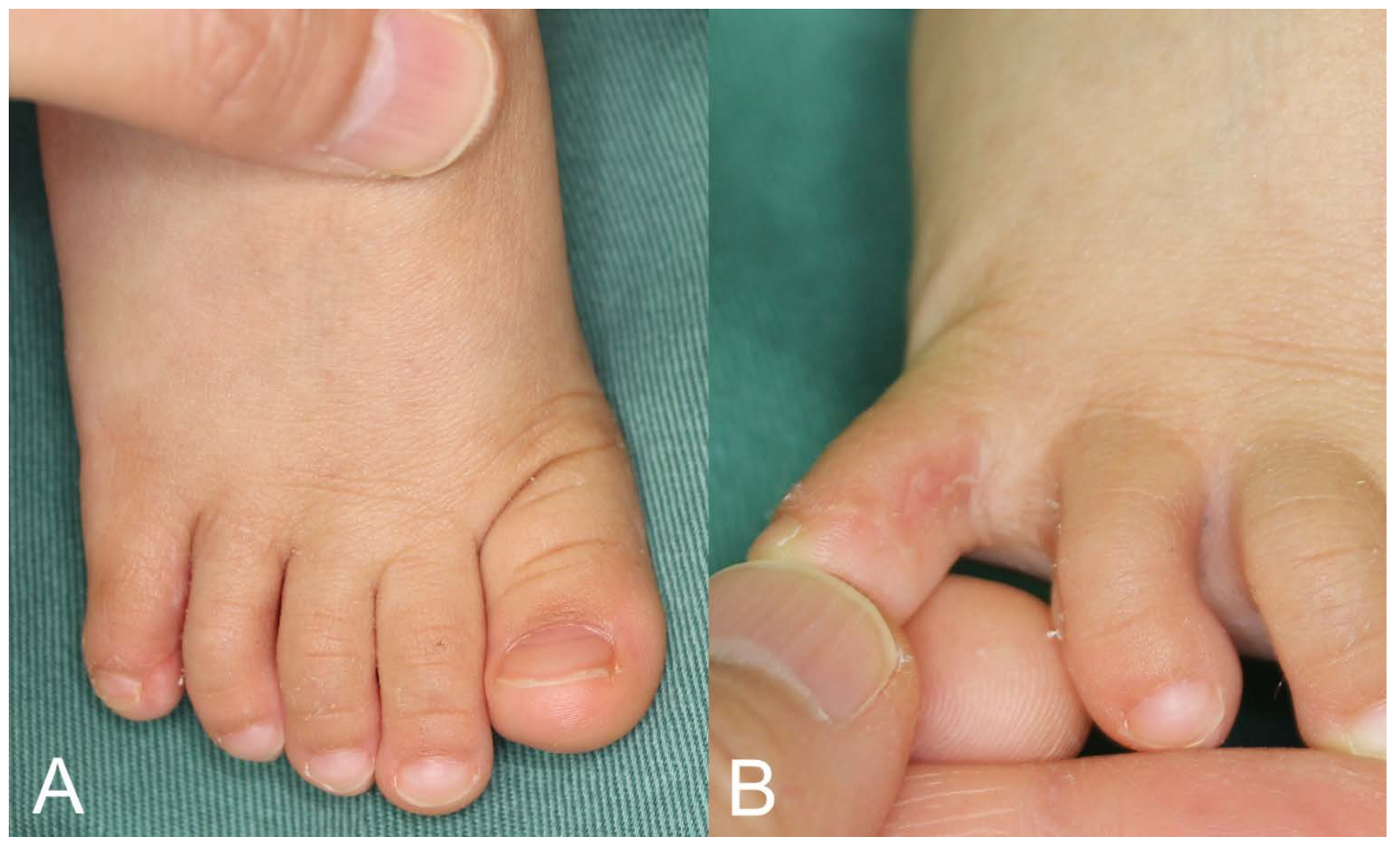

Fig. 6 